
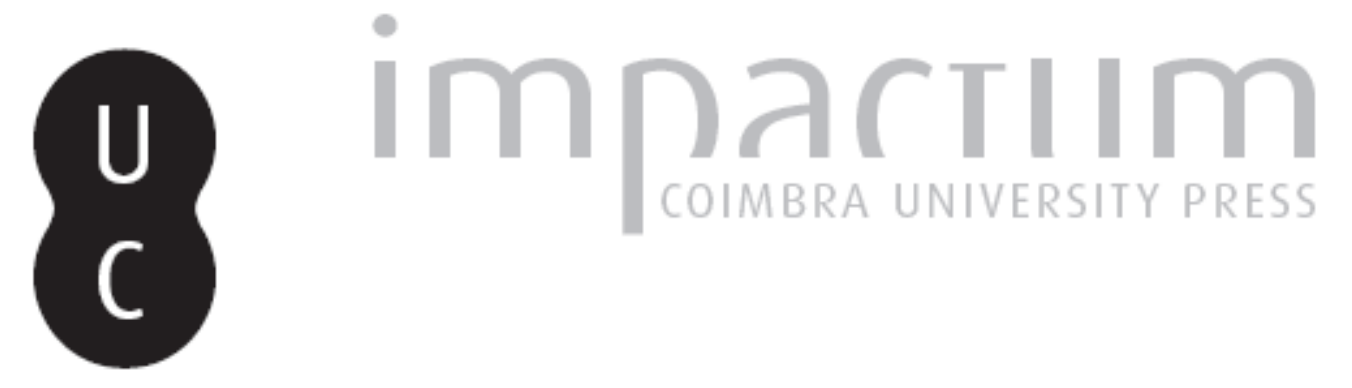

\title{
Breve nota sobre duas cartas de Norton de Matos
}

Autor(es): $\quad$ Magalhães, Joaquim Romero

Publicado por: Imprensa da Universidade de Coimbra

URL persistente:

URI:http://hdl.handle.net/10316.2/45062

DOI:

DOI:https://doi.org/10.14195/2183-8925_5-2_6

Accessed : $\quad$ 26-Apr-2023 13:15:15

A navegação consulta e descarregamento dos títulos inseridos nas Bibliotecas Digitais UC Digitalis, UC Pombalina e UC Impactum, pressupõem a aceitação plena e sem reservas dos Termos e Condições de Uso destas Bibliotecas Digitais, disponíveis em https://digitalis.uc.pt/pt-pt/termos.

Conforme exposto nos referidos Termos e Condições de Uso, o descarregamento de títulos de acesso restrito requer uma licença válida de autorização devendo o utilizador aceder ao(s) documento(s) a partir de um endereço de IP da instituição detentora da supramencionada licença.

Ao utilizador é apenas permitido o descarregamento para uso pessoal, pelo que o emprego do(s) título(s) descarregado(s) para outro fim, designadamente comercial, carece de autorização do respetivo autor ou editor da obra.

Na medida em que todas as obras da UC Digitalis se encontram protegidas pelo Código do Direito de Autor e Direitos Conexos e demais legislação aplicável, toda a cópia, parcial ou total, deste documento, nos casos em que é legalmente admitida, deverá conter ou fazer-se acompanhar por este aviso.

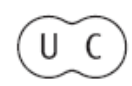




\section{REVISTA DE HISTÓRIA DAS IDEIAS 5}

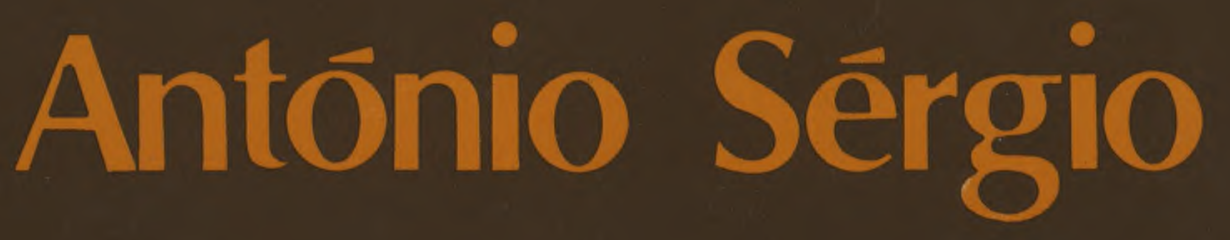

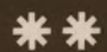

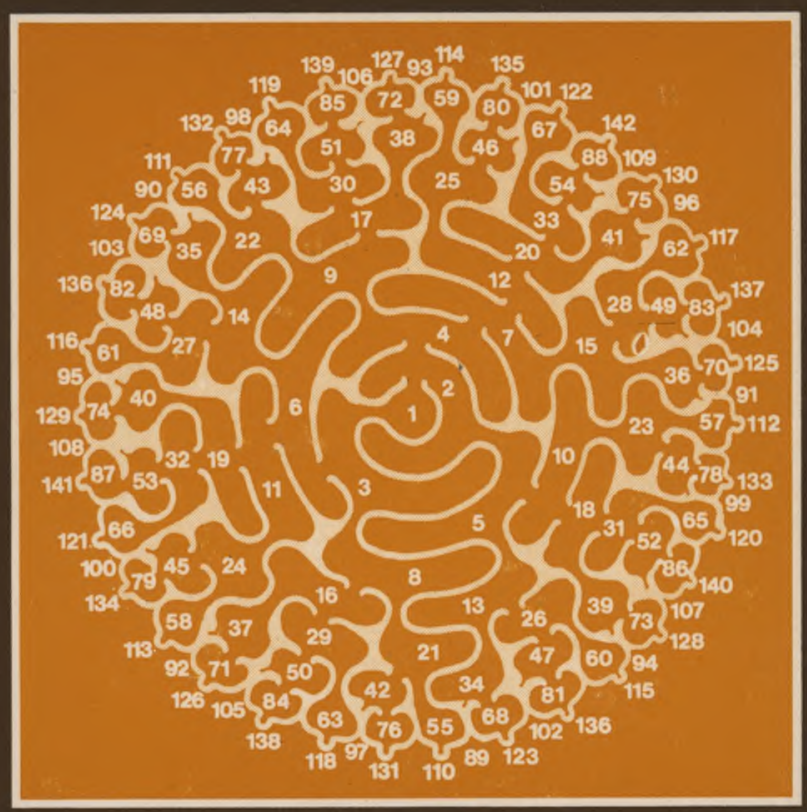

INSTITUTO DE HISTÓRIA E TEORIA DAS IDEIAS FACULDADE DE LETRAS

COIMBRA 1983 


\section{BREVE NOTA SOBRE DUAS CARTAS DE NORTON DE MATOS}

A acção de António Sérgio para derrubar o regime de Salazar tem um traço característico: a teimosia conspirativa. Insiste sempre em encontrar um chefe militar e oficiais capazes de um golpe de Estado. O regime devia ser destruído pelos seus principais sustentáculos. Para tanto não parece que se deixasse impressionar pelo passado daqueles com quem conspirava. $\mathrm{O}$ que era preciso era encontrar quem se dispusesse a levar de vencida o governo e abrir o caminho à Liberdade $\mathrm{f}^{1}$ )Desde o exílio, ou mesmo talvez antes, à frustrada revolta de 11 de Março de 1959, chefiada pelo major Pastor Fernandes, António Sérgio persiste, apostando em General, em Almirante, em Tropa. De entre o grupo castrense que impusera a ditadura devia partir o gesto libertador $\left(^{2}\right)$. A procura de um chefe orienta-se até, muito especialmente, para o campo do inimigo onde poderia encontrar-se o «arrependido» capaz de arrastar camaradas (s).

Se esta linha revela o aristocrata que auténticamente sempre foi, na prática creio que isso se traduz na pouca e distante *

* Faculdade de Economia da Universidade de Coimbra.

(') Na falta de uma história das oposições temos de contar com depoimentos e testemunhos dispersos, especialmente de Raul Rêgo, Fernando Piteira Santos e Manuel Sertório. A mais completa das obras sobre este período é a de Mário Soares, Portugal amordaçado, depoimento sobre os anos de fascismo, Lisboa, Arcádia, 1974.

C) «É curioso que por detrás de quase todos os dissidentes da situação, vindos às fileiras oposicionistas, se pode sempre descortinar o lento trabalho de captação de António Sérgio. Na verdade, Sérgio não foi só um intelectual de primeiríssimo plano e um lutador cívico sempre presente - foi também um conspirador de todos os dias....»: Mário Soares, ob. cit., p. 201.

(3) Ibidem, p. 220. 
colaboração com partidos ou associações partidárias. Vem isto de uma desconfiança nas organizações que tinham já levado à perda da Monarquia constitucional e da República? Alguma coisa. Talvez conjugado com uma apetência pela eficácia da acção governativa sem peias, num País de cidadania pouco esclarecida. O homem real encontrava-se ainda longe do homem ideal do seu apostolado cívico. Não fora iluminado pela Razão estruturante o que só aconteceria pela educação cívica e pela criação de um escol dirigente que destruísse o Reino da Estupidez. Mas não haveria libertação fora da Liberdade, e havia que encontrar quem desse o passo primeiro e indispensável liquidando a ditadura. Assim se afasta mesmo dos que ideologicamente lhe estariam mais próximos, como os componentes da União Socialista (1944), como o vamos ver apagadamente junto do Movimento de Unidade Nacional Anti-Fascista (1943) e do Movimento de Unidade Democrata (1945).

É o que se ouve e lê da acção política - não cuido aqui da cívica - de António Sérgio.

No entanto António Sérgio também participou activamente num projecto para erguer um partido político. Naturalmente socialista ou socializante. Tratou-se de uma Frente Socialista, preparatória de um novo Partido Socialista. Por discordâncias com a União Socialista? Decerto. Foi uma tentativa de reagrupar os elementos que ainda restavam do velho Partido Socialista Português, amalgamado com pequenos grupos que se tinham formado e enquistado e com gente nova que não pertencera a nenhum dos partidos mas que se queria nesse campo ideológico.

A Frente Socialista constituíu-se em 12 de Maio de 1946 «algures em Lisboa» (lê-se no impresso de apresentação), nela ingressando o Partido Socialista Português, o Partido Trabalhista Português e socialistas não filiados em agrupamento algum. Na base as «conclusões» aprovadas numa reunião efectuada em 27 de Janeiro de 1946 no Centro Escolar Republicano Almirante Reis.

Esta frente comum «existirá como tal até à queda da ditadura, momento em que todos os socialistas representados entrarão no Partido Socialista, mediante prévia decisão dos seus Congressos» $\left({ }^{4}\right)$. O Plano nacional de acção fora apresentado por Ramada Curto e aprovado por aclamação. Ramada Curto era ainda presidente da Junta Central do Partido Socia-

(4)

A documentação, creio que inédita, que permitiu esta nota, pertenceu ao Dr. Teófilo Carvalho dos Santos que generosamente me ofereceu várias pastas do seu arquivo pessoal. As cartas publicadas agora são autógrafas. 
lista Português, eleita pelo último congresso, realizado em Coimbra, em 1933.

Depois de uma saudação aos trabalhadores portugueses

- camponeses e operários, da indústria e do comércio - bem como trabalhadores intelectuais, o plano propõe o restabelecimento das liberdades fundamentais - pensamento, consciência, expressão, habeas corpus, associação e reunião, formação e reorganização de partidos políticos e de «controle permanente dos actos governamentais pelos eleitos da Nação e crítica livre dos mesmos actos nos termos da mensagem de Churchill ao povo italiano». Propõe-se a entrada de Portugal na ONU. Aos sindicatos operários se dirige, declarando a sua solidariedade, «mas não enjeita a cooperação de todos os intelectuais que queiram servir os seus princípios, ainda que provenham doutras classes - desde que reconheçam o primado dos interesses proletários». Quer-se participar na «acção Trade-Unionista mundial» e específicamente na «União Internacional dos Sindicatos Operários (Trade-Unions), como a Secção Portuguesa da Internacional Operária (S. P. I. O.)», reclamando a abolição da tutela estatal. Em matéria religiosa condena-se o espírito de intolerância e defende-se a liberdade de todos os cultos, condenando-se que, em nome de doutrinas religiosas, «haja quem se proponha contrariar as legítimas aspirações e interesses dos trabalhadores»». Na parte dedicada à Economia, respeitando-se embora o interesse individual, declara-se que este será sacrificado aos interesses colectivos em caso de conflito. A planificação económica estará de acordo com as realidades: o económico limita o social; as medidas sociais «não se devem realizar, - apenas condicionadas pela lógica, e, justiça das doutrinas, mas de acordo com as realidades e ser rentáveis para a colectividades. Põe então a tónica nos grandes aproveitamentos hidro-eléctricos e na urgência de «efectivar a reforma agrária essencial, base da planifícação económica nacional». A banca emissora devia ser nacionalizada, vindo a constituir com a Caixa Geral dos Depósitos o Banco do Estado Português. O sistema bancário seria reformado e condicionado pelos interesses do Estado e não pelos dos directores e accionistas.

Nacionalizadas seriam também as explorações hidro-eléctricas, transportes ferroviários e marítimos, os Seguros, os Tabacos e os Fósforos. Explica-se que às nacionalizações «preside o princípio de aproveitar todos os técnicos que nelas exercem as suas funções, - de ouvir a opinião dos operários que nelas trabalham - pela criação de legações permanentes dos mesmos junto das suas administrações, (cujas linhas gerais e de interesse colectivo o Estado se limitará a determinar) tornando assim inteiramente impossível o comunismo buro- 
crático e parasitário, - grande mal de todos os regimes capitalistas». Em Educação seria elaborado um plano para durante 5 anos acabar com o analfabetismo. A orientação profissional merece destaque como meio de «se fornecer ao País uma élite intelectual, - única admissível, - para exercer as funções directivas, ao serviço do interesse nacional». Preconiza-se «a integral reforma dos métodos de recrutamento do professorado das Escolas Superiores, e Universidades». Devem criar-se imediatamente seguros sociais. A Justiça deverá ser mais barata. Abolir-se-á a sucessão abintestato excepto para filhos, ascendentes directos e cônjuges. Os territórios ultramarinos formarão com Portugal um todo único «sem distinção de elementos raciais» e considera-se dever nacional elevar o nível de higiene, cultura e educação dos portugueses nascidos nesses territórios. Em matéria orçamental recomenda-se a «redução substancial e impiedosa das despesas improdutivas», dizendo-se que absorvem em Portugal metade dos réditos públicos.

Era este, em resumo, o programa que a Frente devia propor «no caso de em Portugal vir a ser possível a pública e livre discussão desses problemas»».

Ramada Curto - e certos tópicos não deixam de ter um arzinho da linguagem de Oliveira Martins tal como Sérgio a empregava - viu este plano aprovado por aclamação. A partir dele se estabeleceram contactos para a formação de uma comissão executiva e de comissões de estudo por especialidades. António Sérgio, Viveiros Pinto, Ramada Curto, Carlos Sardinha e Castanheira Lobo - estes pelo menos - fazem convites a potenciais membros da Frente. Em Janeiro de 1947 já vários grupos tinham aderido. Gente nova, desvinculada, tinha entrado e tinha saído. Não era fácil nem cómodo estruturar um grupo partidário estando vivo o ideal de unidade do M. U. D.. Âlguns dos solicitados consideravam inoportuna a empresa.

António Sérgio e os seus companheiros devem ter então procurado um bom trunfo: conjugar a organização partidária com uma liderança militar. E para isso escolhem, nada menos, que o prestigiado general Norton de Matos. O general, que não era nem fora nunca socialista $\left({ }^{5}\right)$, empenhado como estivera no unitário MUNAF e viria a estar na sua campanha para a presidência da República, recusa entrar na Frente. Coerentemente. Em duas cartas muito serenas mostra bem como o seu empenhamento estava num bloco forte «de oposição contra o fas-

$\left(^{5}\right) \quad$ Norton de Matos, Memórias e trabalhos da minha vida, Lisboa, Editora Marítimo Colonial, Ld.a, vol. I, 1944, p. 72; Idem, OS dois primeiros meses da minha candidatura à presidência da República, Lisboa, ed. Autor, 2. a ed., 1949, pp. 30-31. 
cismo». Esta escolha de Norton de Matos vem revelar que quando Sérgio, mais tarde, vai preferir a candidatura do general Costa Ferreira à de Norton de Matos, ou avançar com a do almirante Quintão Meireles, ou bater-se por Humberto Delgado em detrimento de Jaime Cortesão está a seguir, tão-só, uma linha de coerência $\left.{ }^{6}\right)$. Exclusivamente política, não pessoal nem ideológica.

A Frente Socialista «tem por objectivo transformar-se, em ocasião oportuna, num partido socialista único, propõe-se trabalhar pelo progresso económico e social do País, pela defesa dos interesses das classes trabalhadoras, pelas liberdades populares e pela gradual instauração de um regime de planificação económica, onde a produção seja realizada com o objectivo primacial da satisfação das necessidades de todos, devendo tal regime ser promovido e fiscalizado pelos representantes de toda a população, em igualdade de direitos políticos». A definição é indiscutivelmente de Sérgio ${ }^{7}$ ). A Frente vai morrer. Como tantas outras da frustração oposicionista. E com ela, creio, a única intervenção deste tipo de Sérgio. Fique a breve nota. Para que conste.

\section{CARTAS}

Lisboa, Travessa da Bela Vista, á Lapa, 5-2. ${ }^{\circ}$

22 de Dezembro de 1946

$$
\text { Ex. }{ }^{m o} \text { Sr. Doutor Antonio Sergio }
$$

Lisboa

Meu muito Prezado Amigo:

Tenho presentes palavras da «Frente Socialista», assinadas por V. ${ }^{\text {a }}$ Ex. ${ }^{\mathrm{a}}$ e pelos Srs. Dr. Ramada Curto, Carlos Sardinha e Castanheira Lobo, que muito estimei 1 er e que agradeço muito penhorado.

Creio que a «Frente Socialista» deve empregar todos os esforços, compativeis com a intransigencia que é indispensável manter em relação aos actuais governantes e ao regime em vigor, para se constituir em partido político e poder abertamente fazer propaganda e apresentar estudos, trabalhos e projectos, tendentes a conseguir a modificação completa, em breves anos, da triste vida da população de Portugal e o estabelecimento de justiça social que entre nós não existe.

Sem desejar ingressar em qualquer partido, sendo meu dever conservar-me onde sempre estive, como Liberal e Democrata, pois a minha idade me aconselha a deixar aos novos as novas tarefas na-

${ }^{6}$ Como se sabe António Sérgio colaborou na campanha de Norton de Matos com extraordinárias páginas de polémica política.

(7) Autógrafo. 
donáis, sou de opinião que para levar a cabo aquela profunda modificação são necessários partidos diversos, muito diversos, dos que existiram.

Ao «Partido Socialista unico» que muito desejaria ver em actuação, darei a minha inteira solidariedade, com a certeza de que ele será altamente benefico para o estabelecimento da vida sã, sem miséria e sem medo, que todos desejamos. deração,

Aceitem V. ${ }^{3 *}$ Ex. ${ }^{\text {as }}$ os protestos da minha mais elevada consi-

a) Norton de Mattos

Lisboa, 16 de Fevereiro de 1947

Ex. ${ }^{\mathrm{m}}$ O Sr. Doutor Antonio Sergio:

Meu muito Prezado Amigo:

Que dizer-lhe mais sobre o que lhe tenho dito e escrito sobre a Frente Socialista?

O meu desejo seria que os Socialistas portugueses soubessem e pensassem nesta altura da vida politica do paiz unir-se num movimento unico que, pondo de parte quaisquer divergencias, constituissem um forte bloco de oposição contra o fascismo.

Teria esse facto palpaveis vantagens presentes e futuras.

Mas não sendo isso possivel, e sendo o caso que o Antonio Sergio, o Ramada Curto e tantos outros democratas, a quem muito considero, conseguirem realizar, em breve parte, essa aspiração com a organização da Frente Socialista, mais uma vez venho dar a essa Frente oposicionista o meu encorajamento no seu proposito de derrubar o Fascismo e de bem resistir entretanto com todos os meios ao seu alcance.

Escusado será dizer-lhe, meu bom Amigo, que os esforços da Frente Socialista terão de contar inteiramente com os dos outros movimentos de oposição ao fascismo.

Se as oposições ao fascismo (e desgraça é que eu tenha de dizer isto por ver que não ha uma oposição unica, como tanto será para desejar) não trabalharem harmónicamente e se cada uma delas passar a puxar para o seu lado, nada se conseguirá.

Creio que os fascistas nos ensinaram cousas que são de aproveitar temporariamente:-para se manterem criaram o partido unico; para os derrubarmos teremos de constituir a Frente Unica de Oposição.

Mando-lhe as minhas amigas saudações e os meus desejos da melhor sorte

a) Norton de Mattos 